\title{
Jornadas de Otoño SER 2015: desafíos de la salud respiratoria en Chile
}

\author{
SER 2015 Fall meeting: "Challenges of Respiratory Health in Chile"
}

Como es tradicional en la última semana de marzo de 2015 celebramos las Jornadas de Otoño en su versión $N^{\circ}$ 34. La Sociedad Chilena de Enfermedades Respiratorias (SER) ha destinado estas jornadas a los especialistas, es decir a sus socios ofreciéndoles programas con temas de interés y novedosos dirigidos especialmente a las nuevas generaciones.

Este año siguiendo la tradición el tema fue "Desafios de la salud respiratoria en Chile". Se discutió sobre el futuro de la medicina respiratoria acercándonos a conocer "las causas de las causas" de la enfermedad respiratoria.

Estas jornadas fueron coordinadas por el Dr. Gonzalo Valdivia C., quien hizo una interesante exposición sobre los determinantes sociales en salud cuyo marco conceptual motivó el último editorial de esta revistal.

Las jornadas se iniciaron con un sentido homenaje en memoria del Profesor Dr. Edgardo Carrasco Calderón (QEPD) realizado por el presidente de la SER Dr. Mario Calvo G. En este homenaje se recordó el gran aporte que el Dr. Carrasco hizo a la SER ${ }^{2}$. En esta Sociedad él fue un destacado presidente, fundó la revista que se transformó en el órgano oficial de la SER y fue nombrado Maestro de la especialidad. Dirigió durante 15 años el actual Instituto Nacional del Tórax y formó a innumerables especialistas nacionales y extranjeros. En su trabajo clínico y de investigación destacó por sus valiosos aportes en asma bronquial, enfermedades pulmonares obstructivas y en el área de la alergia e inmunología respiratorias. Su figura ha dejado una huella indeleble en la SER y en la Medicina respiratoria de nuestro país.

La mañana del primer día de las jornadas fue dedicada a conocer los problemas actuales de nuestra especialidad y el origen de las enfermedades respiratorias enfatizando la importancia del embarazo donde comienzan a gestarse los problemas crónicos a que estamos enfrentados. Los conferencistas se dedicaron a analizar la influencia del género y de los factores psicosociales en el desarrollo de las enfermedades respiratorias.

Después de un almuerzo en que pudimos conversar con colegas amigos de larga data, en la tarde del primer día de las jornadas se desarrollaron dos módulos de charlas muy interesantes. Uno para los internistas sobre el desafio de las enfermedades ocupacionales, organizado por la Comisión de Enfermedades Ocupacionales liderada por el Dr. Gustavo Contreras T. y otro para los pediatras dedicado a un tema emergente, la pediatría ambiental, que nos permitió adentrarnos en conocer sobre cómo impacta el medio ambiente desde la niñez en la etiopatogenia de las enfermedades. También se trató el tema de cómo abordar los problemas respiratorios de nuestro país, desde un punto de vista epidemiológico.

El programa de las jornadas continuó con un reconocimiento al presidente de la SER Dr. Mario Calvo por su reciente nombramiento realizado en Valdivia, como Miembro Correspondiente de la Academia Chilena de Medicina ${ }^{3}$. Es motivo de orgullo para nuestra Sociedad contar actualmente con 4 socios que han sido elegidos miembros de esta selecta academia. Sus nombres se agregan a los presidentes fundadores y a los de algunos de sus connotados y antiguos sucesores que también formaron parte de esta Academia fundada en 1964.

Terminamos la jornada del primer día asistiendo a una extraordinaria conferencia pronunciada por 
nuestra profesora invitada Dra. Lucía Cifuentes O., genetista del Instituto de Ciencias Biomédicas, Facultad de Medicina, Universidad de Chile, sobre los orígenes y diversidad genética de la población chilena.

Considerando que la Sociedad fue fundada el 13 de marzo de 1930 con el nombre de Sociedad Chilena de Tisiología, el directorio y el comité organizador estimaron que en estas jornadas era oportuno conmemorar debidamente los 85 años de existencia de nuestra Sociedad por lo que se realizó una cena especial de camaradería entre los socios.

La mañana del segundo día de las jornadas comenzó con una objetiva puesta al día sobre trasplantes pulmonares en Chile, cómo se están realizando y que falta aún por hacer para mejorar la situación de nuestro país en este importante tema de nuestra especialidad.

A continuación pudimos asistir a una serie de actividades académicas destinadas a conmemorar el $85^{\circ}$ aniversario de la fundación de la Sociedad. Éstas se iniciaron con un relato sobre el aporte de la medicina respiratoria al país pronunciado por nuestro socio y ex ministro de salud, Dr. Jorge Jiménez de la Jara. Luego fue analizado el desarrollo de la SER en sus 85 años de existencia en una conferencia del Dr. Manuel Barros M. en tanto que la visión sobre el futuro de la SER fue expuesta por el Dr. Francisco Arancibia H., actual vicepresidente y próximo presidente de la SER. Estas dos conferencias por su importancia documental han sido publicadas en este mismo número de la revista ${ }^{4,5}$. Los actos conmemorativos de este aniversario de la SER culminaron con la entrega de un reconocimiento a cada uno de los presidentes de la SER en el último decenio. Es así como recibieron este reconocimiento los Drs. Raúl Corrales V., Fernando Rivas B., Fernando Descalzi M., Carolina Herrera C. y Luis Astorga F.

Al finalizar estas jornadas el balance académico que ellas nos han dejado nos ha parecido exitoso ya que los objetivos propuestos se han logrado con las actividades programadas, las cuales fueron bien recibidas por los especialistas en enfermedades respiratorias. Confiamos en continuar realizando anualmente estas ya tradicionales jornadas de nuestra Sociedad y esperamos que nuestros socios sigan participando en ellas con entusiasmo, dedicación y alegría.

Dra. Patricia Díaz A. Coordinadora Comité Cientifico Sociedad Chilena de Enfermedades Respiratorias Email:pdiaz@med.uchile.cl

\section{Bibliografía}

1.- VALDIVIA G. Hacia el control radical de las enfermedades respiratorias: un alto en el camino. Rev Chil Enferm Respir 2015; 31: 5-7.

2.- CALVO M. In memoriam Profesor Edgardo Carrasco Calderón (1928-2015). Rev Chil Enferm Respir 2015; 31: 37-8.

3.- Dr. Mario Calvo Gil nombrado miembro correspon- diente de la Academia Chilena de Medicina. Rev Chil Enferm Respir 2015; 31: 61-3.

4.- BARROS M. Visión Histórica de la Sociedad Chilena de Enfermedades Respiratorias en sus 85 años. Rev Chil Enferm Respir 2015; 31: 109-16.

5.- ARANCIBIA F. Visión de futuro de la Sociedad Chilena de Enfermedades Respiratorias. Rev Chil Enferm Respir 2015; 31: 117-20. 